\title{
氨基葡萄糖衍生物配体在不对称合成中的应用进展
}

\author{
宋沙沙周宏勇李小娜王丽华李云庆王家喜*
}

(河北工业大学化工学院 天津 300130)

\begin{abstract}
摘要 氨基葡萄糖是广泛存在于自然界的手性天然产物壳聚糖的降解产物，多手性中心及强的配位能力使之成为制备 手性胺基、胺基/膦基配体的理想原料. 氨基葡萄糖衍生物作为手性配体参与的不对称反应已成为有机化学中非常活跃 的研究领域. 综述了氨基葡萄糖衍生物在不对称烯丙基烷基化、Heck 反应、1,4-共轭加成反应、烯烃的环氧化反应、 烯烃环丙化等反应的最新研究进展.
\end{abstract}

关键词 手性配体; 氨基葡萄糖; 金属络合物; 不对称合成

\section{Advance of Glucosamine and Their Derivatives as Chiral Ligands in Asymmetric Syntheses}

\author{
Song, Shasha \\ Zhou, Hongyong \\ Li, Xiaona \\ Wang, Lihua \\ Li, Yunqing \\ Wang, Jiaxi* \\ (School of Chemical Engineering, Hebei University of Technology, Tianjin 300130)
}

\begin{abstract}
Glucosamine is a chiral compound degraded from widely existed natural product chitosan. It is becoming an ideal raw material for preparation chiral amine, amine/phosphine ligands due to its more chiral centers and strong coordination ability. The application of glucosamine derivatives as chiral ligands in asymmetric organic reactions has become a very active research area. In this paper, the application of glucosamine derivatives in asymmetric allylic alkylation, Heck reaction, 1,4conjugate addition reaction, epoxidation reaction of olefins and cyclopropanation of olefin has been reviewed.
\end{abstract}

Keywords chiral ligand; glucosamine; metal complex; asymmetric synthesis

不对称合成是当今化学发展最为活跃的领域之一, 在开发手性药物、材料及香料等化学品方面具有重要的 意义 ${ }^{[1]}$. 不对称烯丙基烷基化反应 ${ }^{[2]}$. Heck 反应 ${ }^{[3]} 、 1,4-$ 共轭加成反应 ${ }^{[4]}$ 、烯烃的手性环丙化反应 ${ }^{[5]}$ 、醛不对称

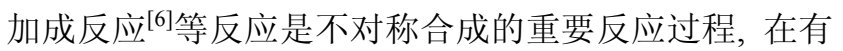
机合成中发挥着重要的作用. 手性配体在不对称催化中 具有重要作用, 开发新型高效的手性配体一直是人们研 究的热点. 糖类是一类廉价的手性天然产物, 近年来糖 类衍生物作为不对称合成的手性配体日益广泛, 糖骨架 手性配体合成、糖基含膦配体及糖衍生物作为手性助剂 在立体选择性合成中的应用已有综述 ${ }^{[79]}$. 氨基葡萄糖 具有糖类多官能团和多手性中心的优点, 易于功能化 (如图 1 箭头所示)合成出特定结构的配体, 具有潜在的 诱导手性能力. 目前文献报道的氨基葡萄糖衍生物配体 主要有噁唑啉类、酰胺类、席夫碱类、氨基醇类等, 氨
基葡萄糖衍生物参与的不对称反应研究也越来越引起 关注，但还未见相关的综述. 本文从氨基葡萄糖衍生物 参与的催化反应角度综述了氨基葡萄糖衍生物配体在 不对称合成中的应用.

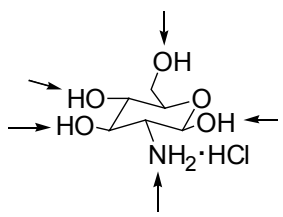

图 1 氨基葡萄糖可改性的位置

Figure 1 The plausible modified position of glucosamine

\section{1 不对称烯丙基烷基化反应}

钯催化烯丙基烷基化反应是有机合成中重要的有

*E-mail: wangjiaxi@hebut.edu.cn

Received October 14, 2013; revised December 5, 2013; published online December 13, 2013.

Project supported by the Natural Science Foundation of Hebei Province (No. B2011202087).

河北省自然科学基金(No. B2011202087)资助项目. 
机反应, 广泛应用于形成不对称碳碳键和碳杂键. 该反 应中用到的手性配体大多数是二齿配体(如 $\mathrm{P} / \mathrm{N}, \mathrm{P} / \mathrm{S}$, $S / N$ 和 $\left.P / P^{\prime}\right)$. 对于一些二取代的底物, $N / P$ 配体表现出高 的对映选择性. 然而随着烯烃上取代基的增多及立体位 阻的增大, 催化反应的速度及选择性仍有很大挑战. 目 前, 在烯丙基烷基化反应中应用的氨基葡萄糖衍生物配 体主要有二芳基膦噁唑啉类、亚磷酸酯噁唑啉类、膦酰胺类、席夫碱类. 催化效果好的实验列于表 1 中, 不 对称烯丙基烷基化反应通式如 Eq. 1.

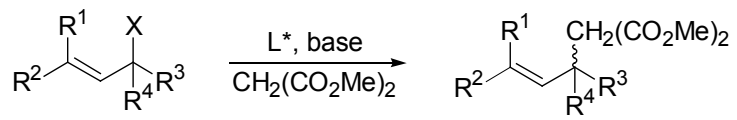

S1 $R^{1}=R^{3}=H, R^{2}=R^{4}=P h, X=O A C$

S2 $R^{1}=R^{3}=H, R^{2}=R^{4}=P h, X=\mathrm{OCO}_{2} E t$

S3 $R^{1}=R^{3}=H, R^{2} R^{4}=\left(C_{2}\right)_{3}, X=O A C$

S4 $R^{1}=R^{3}=H, R^{2}=R^{4}=M e, X=O A C$

S5 $\mathrm{R}^{1}=\mathrm{R}^{3}=\mathrm{H}, \mathrm{R}^{2}=\mathrm{R}^{4}=i-\operatorname{Pr}, \mathrm{X}=\mathrm{OAC}$

\section{1 二芳基膦噁唑啉配体}

Yonehara 等 ${ }^{[10 \sim 12]}$ 将配体 $\mathbf{1 a} \sim 1 \mathrm{~g}$ (Eq. 2) 用于催化烯 丙基烷基化反应取得较好的实验结果. 在甲苯中以 $\left[\mathrm{Pd}\left(\eta^{3}-\mathrm{C}_{3} \mathrm{H}_{5}\right) \mathrm{Cl}\right]_{2}$ 和配体 1a 原位生成的催化剂催化底物 S1 的烯丙基烷基化反应, 对映体选择性达到 $96 \% e e$ (表 1, Entry 1). 1 $\mathrm{c}$ 和 1e 为配体时产物的对映体选择性为 95\%和 94\% ee(表 1, Entries 4, 6). 含有庞大取代基的配 体 1d 和 1f 参与反应产物的对映选择性较低(表 1 , Entries $3,7)$. 从表 1 中可以看出反应的催化活性及立体选择性 与底物及配体的结构相关, 噁唑啉部分的取代基 $\mathrm{R}$ 体积 小时催化效果较好. 底物 $\mathbf{S} 2$ 反应得到类似的结果, $1 \mathrm{a}$ 及 $1 \mathrm{c}$ 参与反应的 $e e$ 值分别可达 $94 \%$ 和 $95 \%$ (表 1, Entry 2), 说明离去基团 X 对反应影响不大. 配体 $\mathbf{1 a}$ 参与底物 $\mathbf{S 3}$ 的烯丙基烷基化反应 $e e$ 值最高可达 74\%(表 1, Entry 3).

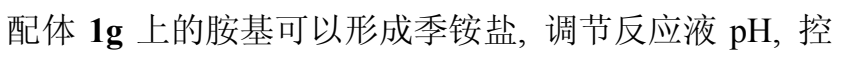
制氨基季胺化反应及其逆反应实现催化剂在油-水相的 循环使用, 配体 $1 \mathrm{~g} / \mathrm{Pd}$ 催化 $\mathrm{S1}$ 的烯丙基烷基化反应对映 选择性 $92 \%$ ee (表 1, Entry 8), 催化剂 1 次循环使用的产 物收率 79\%，对映选择性 $92 \%$ ee.
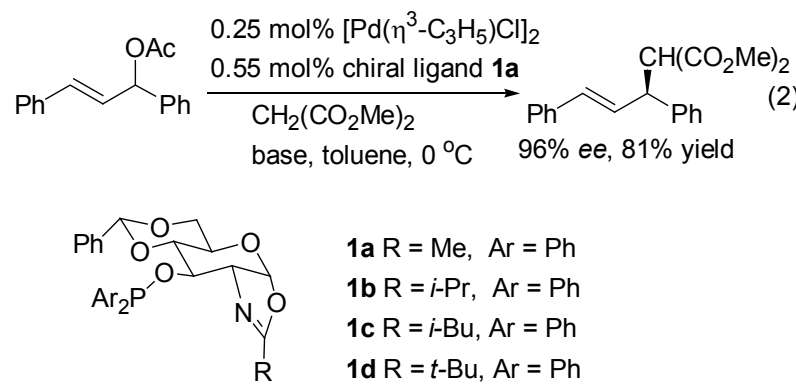

$$
\begin{aligned}
& \text { 1a } \mathrm{R}=\mathrm{Me}, \mathrm{Ar}=\mathrm{Ph} \\
& \text { 1b } \mathrm{R}=i-\mathrm{Pr}, \mathrm{Ar}=\mathrm{Ph} \\
& \text { 1c } \mathrm{R}=i-\mathrm{Bu}, \mathrm{Ar}=\mathrm{Ph} \\
& \text { 1d } \mathrm{R}=t-\mathrm{Bu}, \mathrm{Ar}=\mathrm{Ph} \\
& \text { 1e } \mathrm{R}=\mathrm{Ph}, \mathrm{Ar}=\mathrm{Ph} \\
& \text { 1f } \mathrm{R}=\mathrm{PhCH}, \mathrm{Ar}=\mathrm{Ph} \\
& \text { 1g } \mathrm{R}=\mathrm{Me}, \mathrm{Ar}=p-\mathrm{Et}_{2} \mathrm{NCH}_{2} \mathrm{C}_{6} \mathrm{H}_{4}
\end{aligned}
$$

表 1 氨基葡萄糖衍生物/钯催化体系催化底物 S1 的烯丙基烷 基化反应

表 1 Asymmetric allylic alkylation of S1 catalyzed by palladium/glucosamine derivatives

\begin{tabular}{cccccc}
\hline Entry & L & Conv./\% & Yield/\% & $e e / \%$ & Ref. \\
\hline 1 & $\mathbf{1 a}$ & & 81 & $96(S)$ & {$[10]$} \\
2 & $\mathbf{1 a}$ & & 84 & $95(S)$ & {$[11]^{a}$} \\
3 & $\mathbf{1 a}$ & & 88 & $74(R)$ & {$[11]^{b}$} \\
4 & $\mathbf{1 c}$ & & 82 & $95(S)$ & {$[10]$} \\
5 & $\mathbf{1 d}$ & & 91 & $83(S)$ & {$[10]$} \\
6 & $\mathbf{1 e}$ & & 74 & $94(S)$ & {$[10]$} \\
7 & $\mathbf{1 f}$ & & 88 & $78(S)$ & {$[10]$} \\
8 & $\mathbf{1 g}$ & & 95 & $92(S)$ & {$[12]$} \\
9 & $\mathbf{2 a}$ & 100 & & $92(S)$ & {$[16]$} \\
10 & $\mathbf{3 a}$ & 92 & & $86(S)$ & {$[16]$} \\
11 & $\mathbf{2 b}$ & 89 & & $84(S)$ & {$[16]$} \\
12 & $\mathbf{2 c}$ & 95 & & $86(S)$ & {$[16]$} \\
13 & $\mathbf{2 d}$ & 85 & & $89(S)$ & {$[16]$} \\
14 & $\mathbf{2 e}$ & 57 & & $86(S)$ & {$[16]$} \\
15 & $\mathbf{2 f}$ & 82 & & $81(S)$ & {$[16]$} \\
16 & $\mathbf{2 g}$ & 80 & & $9(S)$ & {$[16]$} \\
17 & $\mathbf{2 h}$ & 100 & & $84(S)$ & {$[16]$} \\
18 & $\mathbf{2 i}$ & 99 & & $62(S)$ & {$[16]$} \\
19 & $\mathbf{5 a}$ & 100 & & $85(S)$ & {$[16]$} \\
20 & $\mathbf{6 a}$ & 99 & & $80(S)$ & {$[16]$} \\
21 & $\mathbf{8 a}$ & 100 & 98 & $83(R)$ & {$[20]$} \\
22 & $\mathbf{1 0 a}$ & 100 & 95 & $76(R)$ & {$[22]$} \\
23 & $\mathbf{1 0 b}$ & 100 & 96 & $86(R)$ & {$[22]$} \\
24 & $\mathbf{1 0 c}$ & 100 & 99 & $66(R)$ & {$[22]$} \\
25 & $\mathbf{1 3 c}$ & 100 & 98 & $87(S)$ & {$[23]$} \\
26 & $\mathbf{1 3 e}$ & 100 & 97 & $82(S)$ & {$[23]$} \\
27 & $\mathbf{1 4 d}$ & & 95 & $90(S)$ & {$[24]$} \\
28 & $\mathbf{1 5}$ & & 80 & $88(S)$ & {$[25]$} \\
29 & $\mathbf{1 6}$ & & 100 & $90(S)$ & {$[26]$} \\
\hline
\end{tabular}

\section{2 亚磷酸酯噁唑啉类配体}

Mata 等 ${ }^{[13 ~ 16]}$ 在上述配体的基础上把二芳基膦换成 亚磷酸酯设计合成了配体 $2 \sim 6$ (Scheme 1). 此类配体优 点有: (1)建立了一个手性穴(一个底物可以嵌入的手性 穴)方便协调控制有位阻和没有位阻底物的配位，提高 了反应的专一性; (2)亚磷酸酯的 $\pi$ 受体能力高, 提高了 底物的反应活性; (3)亚磷酸酯及噁唑啉部分的功能化, 使得催化剂的催化性能更易调控.

配体 2 6 在不对称烯丙基烷基化反应中的催化性 能(催化反应活性和对映选择性)主要受到噁唑啉上取代 基、手性轴、联苯部分取代基的影响，用含有苯基噁唑 啉配体 2a 催化底物 S1 的反应, 对映选择性为 $92 \% \mathrm{ee}$ (Eq. 3, 表 1, Entry 9). 催化活性随取代基 $\mathrm{R}$ 的增加而降 低(i.e. $\mathrm{Me}>\mathrm{Ph} \approx \mathrm{Bn}>i-\mathrm{Pr}>t-\mathrm{Bu}$, 表 1, Entries $9 \sim 10$, 19 20), 配体 $\mathbf{2} \mathbf{a} \sim 2 \mathbf{i}$ 上联苯邻位取代基对催化活性影 响较大, 对位取代基对对映选择性影响大(表 1, Entries 

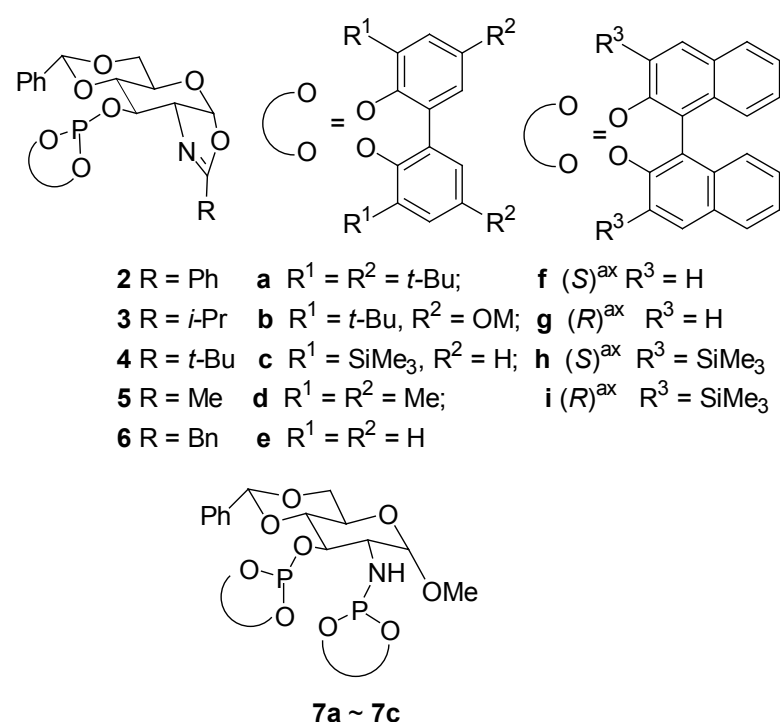

Scheme 1
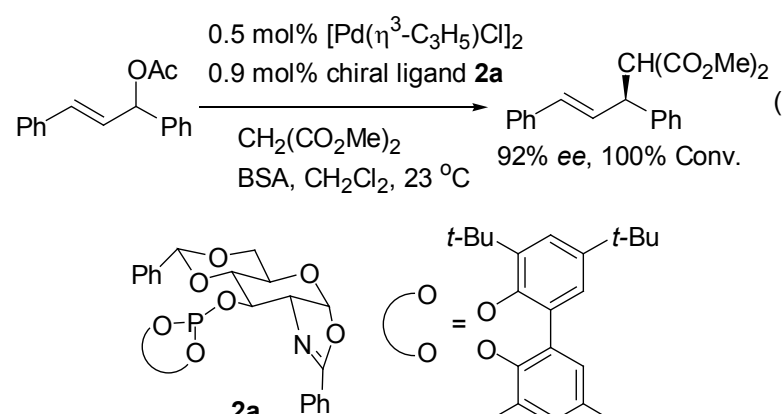<smiles>CC(C)(C)c1cc(-c2cc(C(C)(C)C)cc(C(C)(C)C)c2O)c(O)c(C(C)(C)C)c1</smiles>

$9,11 \sim 18)$, 邻、对位都为叔丁基时反应活性和对映选择 性最高(ligand $\mathbf{2 a}$, 表 1, Entry 9). 配体 $\mathbf{2} \mathbf{f} \sim \mathbf{2} \mathbf{i}$ 中联菜部 分和配体骨架对反应的对映选择性有协同作用(表 1 , Entries 15 18). 配体 7a 参与不对称烯丙基烷基化反应, 线性二取代的 $\mathbf{S 1}, \mathbf{S 5}$ 和环状 $\mathbf{S 3}$ 反应产物的 $e e$ 值分别为 $84 \%, 89 \%, 48 \%$, 对于空间位阻小的 S4 而言, 配体 7c 催 化反应的选择性 $e e$ 为 $61 \%{ }^{[17]}$.

\section{3 膦酰胺配体}

Framery 等 ${ }^{[18 ~ 21]}$ 合成了膦酰胺配体 $8 \sim 12$ (Scheme 2), 配体 $8 \mathrm{a}$ 催化底物 $\mathbf{S 1}$ 烯丙基烷基化反应的转化率及 对映选择性分别为 $100 \%, 83 \%$ (表 1, Entry 21). 配体与钯 的比例增加导致反应的对映选择性下降. $8 \mathrm{a} / \mathrm{Pd}$ 为 $1: 1$ 时, 形成刚性的络合物 $\mathbf{C}_{1}$, 但配体 $8 \mathbf{a}$ 增加到 2 时, 会以 单齿配体形成结构易变的络合物 $\mathbf{C}_{2}$, 导致对映选择性 比较低. 络合物 $\mathbf{C}_{1}$ 和 $\mathbf{C}_{2}$ 存在溶解平衡. 配体 $8 \mathrm{a}$ 催化底 物 S1 和其他亲核试剂的烯丙基烷基化反应也能得到较 高 $e e$ 值的产物. 但催化其他底物的对映体选择性很低. $8 \mathrm{~b}$ 形成的催化剂没有活性. 配体 $9 \mathrm{a} \sim 9 \mathrm{c}$ 中二苯基膦和 氨基之间被两个亚甲基分开，跟钯形成六元环螯合物. 配体 9b 受到 $(S)$-立体效应的影响, 反应产物的 $e e$ 值比配
体 8a 参与反应的高 $(86 \% e e$ ，表 1, Entry 22$)$ ，而 9a 受 $(R)$-立体效应的影响, 产物的 $e e$ 值比配体 $8 \mathbf{a}$ 参与反应的 低(76\% ee, 表 1, Entry 23). 配体 9c 在二苯基膦 $\alpha$-位没 有手性中心, 得到产物的 $e e$ 值为 $66 \%$ (表 1, Entry 24), 说明配体 $\alpha$-位手性中心的重要性. 配体 10 11 催化底 物 S1 烯丙基烷基化反应得到的对映选择性都很低仅在 30\%左右. 配体 12 在苯基和氨基之间有一个亚甲基，可 形成柔性的七元环螯合物，导致对映选择性仅为 $29 \%$.
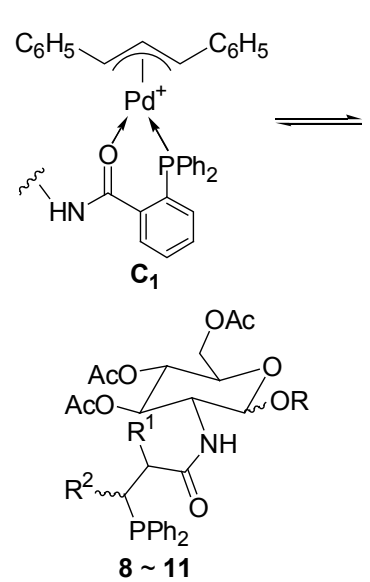
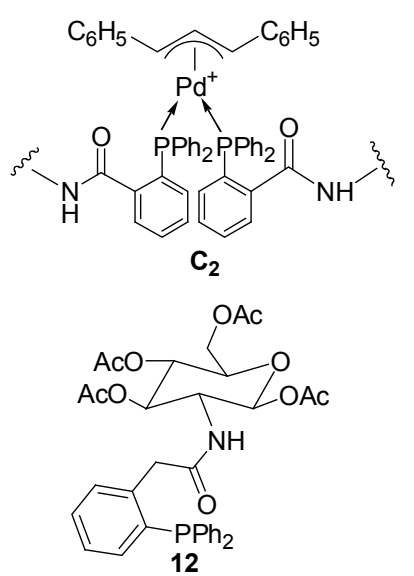

8a $\mathrm{R}=\beta$-OAc, $\mathrm{CHR}^{1} \mathrm{CHR}^{2}=\mathrm{Ph} ; \mathbf{8 b} \mathrm{R}=\alpha-\mathrm{OAc}, \mathrm{CHR}^{1} \mathrm{CHR}^{2}=\mathrm{Ph}$ 9a $\mathrm{R}=\beta-\mathrm{OAc}, \mathrm{R}^{1}=\mathrm{H},(\mathrm{R})-\mathrm{R}^{2}=\mathrm{CH}_{2} \mathrm{CH}_{3} ; 9 \mathrm{~b} \mathrm{R}=\beta-\mathrm{OAc}, \mathrm{R}^{1}=\mathrm{H}$,

$(\mathrm{S})-\mathrm{R}^{2}=\mathrm{CH}_{2} \mathrm{CH}_{3}$ 9c $\mathrm{R}=\beta$-OAc, $\mathrm{R}^{1}=\mathrm{R}^{2}=\mathrm{H}$ 10a $\mathrm{R}=\alpha$-OMe, $\mathrm{CHR}^{1} \mathrm{CHR}^{2}=\mathrm{Ph} ; 10 \mathrm{~b} \mathrm{R}=\beta-\mathrm{OMe}, \mathrm{CHR}^{1} \mathrm{CHR}^{2}=\mathrm{Ph}$ 11a $\mathrm{R}=\alpha-\mathrm{OBn}, \mathrm{CHR}^{1} \mathrm{CHR}^{2}=\mathrm{Ph} ; 11 \mathrm{~b} \mathrm{R}=\beta$-OBn, $\mathrm{CHR}^{1} \mathrm{CHR}^{2}=\mathrm{Ph}$

\section{Scheme 2}

\section{4 席夫碱类配体}

Framery 等 ${ }^{[22]}$ 合成了席夫碱配体 13a 13e (Scheme 3)，研究此类配体在 $\mathbf{S 1}$ 烯丙基烷基化反应中的性能，产 物收率在 $97 \%$ ～99\%，对映选择性在 38\% 87\%之间， 带有丁氧基和苠氧基的配体 $13 \mathrm{c}$ 或 $13 \mathrm{e}$ 参与反应的产物 $e e$ 值较高(分别为 $87 \%, 82 \%$ ), 单糖的 $\beta-1$ 位有庞大的取 代基对配体的不对称诱导是有利的. 当 $\mathrm{Pd} / \mathrm{L}$ 的比例为 $1 / 2$ 时, $25{ }^{\circ} \mathrm{C}$ 反应 $24 \mathrm{~h}$ 后配体 13a, 13b, 13d 参与产物的 收率为 99\%, 97\%，98\%，在同样的反应条件下配体 13c 和 $13 \mathrm{e}$ 参与反应的转化率仅为 $42 \%$. 配体 $13 \mathrm{e}$ 参与的反 应在 $60{ }^{\circ} \mathrm{C}$ 下反应 $24 \mathrm{~h}$ 转化率可达 $100 \%$. 配体 13a, 13b 和 13d 参与反应的 $e e$ 值与 $\mathrm{Pd} / \mathrm{L}$ 比例无关 $(\mathrm{Pd} / \mathrm{L}: 1 / 1 \sim$ $1 / 2)$. 而用 13c 和 13e 为配体时, $\mathrm{Pd} / \mathrm{L}$ 比例增大产物的对 映选择性分别下降至 29\%, 16\% 22\%.

Shen 等 ${ }^{[23]}$ 合成了配体 $14 \mathbf{a} \sim 14 \mathrm{~g}$, 并将其用于催化 $\mathrm{S1}$ 烯丙基烷基化反应. 以配体 14a 为配体时，产物的收 率及 $e e$ 值分别为 $92 \%, 82 \%$. 与 $14 \mathbf{a}$ 相比，对映体选择性 随取代基电子效应及立体效应有关，3，4 位吸电子取代 基有利于提高对映体选择性，如 14b(收率 93\%, ee 值 


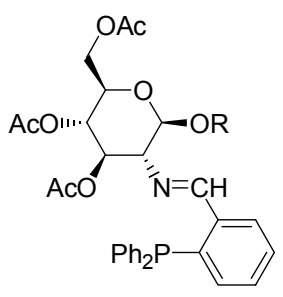

13a $R=A c$

13b $\mathrm{R}=\mathrm{Me}$

13c $\mathrm{R}=t-\mathrm{Bu}$

13d $R=C y$

$13 e \mathrm{R}=\mathrm{Bn}$

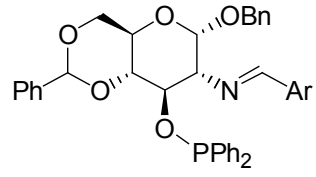

14a $\mathrm{Ar}=\mathrm{Ph}$

14b $\mathrm{Ar}=4-\mathrm{ClC}_{6} \mathrm{H}_{4}$

14c $\mathrm{Ar}=4-\mathrm{CH}_{3} \mathrm{OC}_{6} \mathrm{H}_{4}$

$14 \mathrm{~d} \mathrm{Ar}=4-\mathrm{NO}_{2} \mathrm{C}_{6} \mathrm{H}_{4}$

14e $\mathrm{Ar}=2-\mathrm{CF}_{3} \mathrm{C}_{6} \mathrm{H}_{4}$

$14 \mathrm{Ar}=3-\mathrm{ClC}_{6} \mathrm{H}_{4}$

$14 \mathrm{~g} \mathrm{Ar}=3-\mathrm{NO}_{2} \mathrm{C}_{6} \mathrm{H}_{4}$

83\%)、14f(收率 $84 \%, e e$ 值 $86 \%$ )、14d(收率 $95 \%, e e$ 值 90\%)及 14g(收率 $92 \%$, ee 值 89\%). 含给电子基的配体 $14 \mathrm{c}$ 参与反应产物的对映选择性略微降低 $(75 \% e e)$. 而 邻位连有强吸电子的三氟甲基 14e 的对映选择性降到 $57 \%$, 收率 73\%, 这可能是立体位阻效应所致. 配体 14d 参与底物 S1 与不同亲核试剂反应的收率大部分在 $90 \%$ 左右, $e e$ 值在 $77 \% \sim 92 \%$.

\section{5 其他配体}

Khiar 等 ${ }^{[24,25]}$ 合成了膦-亚胺-硫苷配体及膦-三唑配 体 15 18 (Scheme 3), 配体 15 在 S1 的烯丙基烷基化反 应中得到较好的结果(收率 $80 \%$, ee $88 \%$ ). 配体 16 在乙 腈中 $0{ }^{\circ} \mathrm{C}$ 催化 $\mathbf{S 1}$ 的反应, 产物收率及 $e e$ 值分别为 $100 \%, 80 \%$. 同样的条件, 配体 $\mathbf{1 7}$ 和 $\mathbf{1 8}$ 参与的催化反应 没有对映体选择性, 说明配体 18 参与的反应中可配位 的有机膦是三氮环的配体，与手性糖环较远.
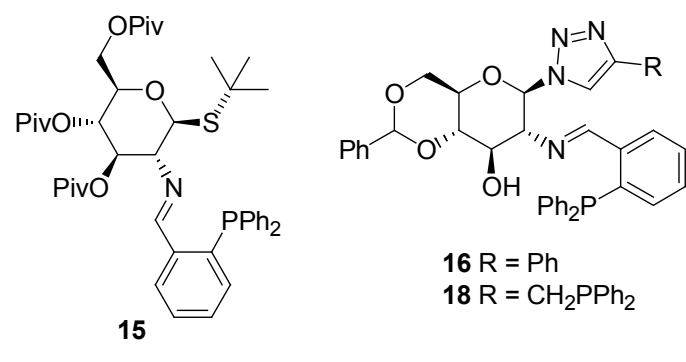<smiles>N[C@H]1[C@H](O)[C@@H]2OC(c3ccccc3)OC[C@H]2O[C@H]1n1cc(CP)nn1</smiles>

Scheme 3

\section{Heck 反应}

Heck 反应广泛应用于形成不对称碳碳键(Eq. 4), 二 苯基膦啞唑啉是该反应常用的配体，反应的区域选择性 和对映选择性较好, 但该类反应还存在反应的时间长及 催化剂价格昂贵的缺点. 为了解决这一问题, 氨基葡萄

糖衍生物参与的催化反应引起了人们的广泛关注.

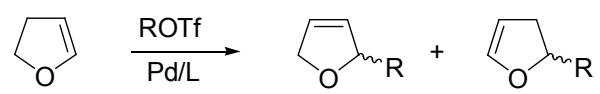

Yonehara 等 ${ }^{[26]}$ 用 $\mathbf{1 a} \sim \mathbf{1 f}$ (Eq. 2) 为配体催化 2,3-二氢 呋喃的芳基化反应，取代基的立体位阻对催化活性影响 较大, 但对立体选择性影响较少. $1 \mathrm{a}$ 为配体时, 产物的 $e e$ 值为 91\%, 收率 88\%(表 2, Entry 1). 立体位阻大的 1d 为配体时催化活性低(24\%), 但选择性不受影响 $(92 \%$ $e e$ (表 2, Entry 4). 含芳烃及苠基的 1e 及 $1 \mathrm{f}$ 为配体时催 化剂催化活性分别为 $96 \%, 100 \%$, 区域选择性都为 100\% (Eq. 5). 配体 1a 1f 在巴豆醇的催化芳基化反应 中催化活性及立体选择性都很低, 但这是第一个用潜手 性无环烯烃的 Mizoroki-Heck-type 分子间不对称反应的 例子.

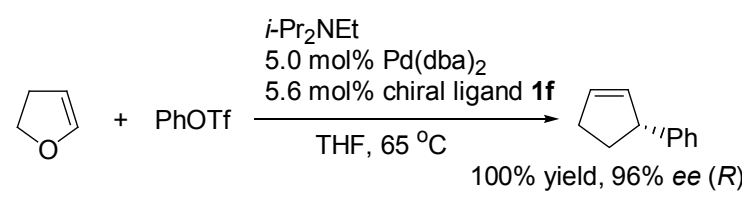

Mata 等 ${ }^{[13,14]}$ 将亚磷酸酯啞唑啉类配体 $\mathbf{2} \sim \mathbf{5}$ (Scheme 1)用于催化 Heck 反应, 催化反应的催化活性、 区域选择性和对映选择性同时受到亚磷酸酯和啞唑啉 部分取代基的影响, 部分催化结果列于表 2 中, 从表 2 中的结果可以看出, 随取代基 $\mathrm{R}$ 体积的增大反应活性和 选择性都会降低(i.e., $\mathrm{Ph}>i-\mathrm{Pr}>t-\mathrm{Bu})$. 联芳基邻位连有 叔丁基的配体 $\mathbf{2 a} \sim 2 \mathrm{c}$ 比 $\mathbf{2 d}$ 和 $\mathbf{2 e}$ 有较高的反应活性和 选择性(表 2, Entries 7 11), 2c 为配体时反应活性相对 最高，区域选择性高达 97\%，对映选择性高达 99\%(表 2, Entry 9), 这表明配体中联芳基邻位有体积大的取代基 有利于提高催化活性. $2 \mathrm{f}$ 和 $\mathbf{2 g}$ 催化的结果表明联苯部分 取代基和配体骨架对反应的对映选择性有协同作用(表 2, Entries 12 13). 总体来说用配体 $\mathbf{5 c}$ 得到最好的结果 (表 2, Entry 16). R=1-naphthyl, $\mathrm{Ph}$ 时对映选择性较高, $\mathrm{R}$ 为吸电子基团时区域选择性较高. 用配体 $\mathbf{2 a}$ 催化其他 底物的 Heck 反应都得到了较好的结果, 见 Scheme 5 .

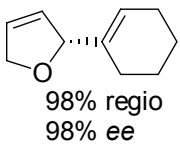

$98 \%$ ee

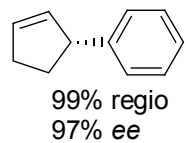

Scheme 5

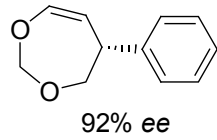

$92 \%$ ee
Amini 等 ${ }^{[27]}$ 只用氨基葡萄糖盐酸盐与钯的化合物催 化芳碘化物和芳溴化物的 Heck 反应，转化率较高. PhI 和苯乙烯反应转化率能达到 $95 \%$. 其他芳碘化物和芳溴 化物的转化率也较高(Eq. 6). 
表 2 亚磷酸-噁唑啉配体/钯催化 2,3-二氢呋喃不对称芳基化 反应

表 2 Asymmetric Phenylation of 2,3-Dihydrofuran Catalyzed by $\mathrm{Pd} /$ Phosphite-oxazoline Ligands

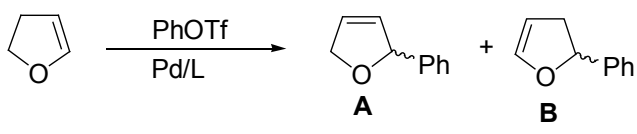

\begin{tabular}{|c|c|c|c|c|c|c|c|}
\hline \multirow{2}{*}{ Entry } & \multirow{2}{*}{ Ligand' } & \multirow{2}{*}{ Time/d } & \multirow{2}{*}{ Yield/\% } & \multirow{2}{*}{$\begin{array}{c}\text { Conv. } / \% \\
(\mathbf{A}: \mathbf{B})\end{array}$} & \multicolumn{2}{|c|}{$e e / \%$} & \multirow{2}{*}{ Ref. } \\
\hline & & & & & $\mathbf{A}$ & B & \\
\hline 1 & 1a & 4 & 88 & & $91(R)$ & & [27] \\
\hline 2 & $1 b$ & 3 & 84 & & $88(R)$ & & [27] \\
\hline 3 & $1 \mathrm{c}$ & 3 & 100 & & $93(R)$ & & [27] \\
\hline 4 & 1d & 3 & 24 & & $92(R)$ & & [27] \\
\hline 5 & $1 \mathrm{e}$ & 2 & 96 & & $86(R)$ & & [27] \\
\hline 6 & 1f & 1 & 100 & & $96(R)$ & & [27] \\
\hline 7 & $2 a$ & 1 & & $\begin{array}{c}98 \\
(87: 13)\end{array}$ & $97(R)$ & $88(R)$ & [14] \\
\hline 8 & $2 b$ & 1 & & $\begin{array}{c}86 \\
(85: 15)\end{array}$ & $97(R)$ & $89(R)$ & [14] \\
\hline 9 & $2 c$ & 1 & & $\begin{array}{c}100 \\
(97: 3)\end{array}$ & $99(R)$ & nd & [14] \\
\hline 10 & $2 d$ & 1 & & $\begin{array}{c}42 \\
(72: 28)\end{array}$ & $25(R)$ & $16(R))$ & [14] \\
\hline 11 & $2 e$ & 1 & & $\begin{array}{c}45 \\
(60: 40)\end{array}$ & $80(R)$ & $69(R)$ & [14] \\
\hline 12 & $2 f$ & 1 & & $\begin{array}{c}32 \\
(58: 42)\end{array}$ & $6(R)$ & $19(R))$ & [14] \\
\hline 13 & $2 \mathrm{~g}$ & 1 & & $\begin{array}{c}28 \\
(55: 45)\end{array}$ & $73(R)$ & $4(R)$ & [14] \\
\hline 14 & $3 \mathbf{a}$ & 1 & & $\begin{array}{c}80 \\
(71: 29)\end{array}$ & $84(R)$ & $90(R)$ & [14] \\
\hline 15 & $4 a$ & 1 & & $\begin{array}{c}12 \\
(65: 35)\end{array}$ & $83(R)$ & $23(R)$ & [14] \\
\hline 16 & $5 c$ & 1 & & $\begin{array}{c}100 \\
(98: 2) \\
\end{array}$ & $99(R)$ & nd & [13] \\
\hline
\end{tabular}
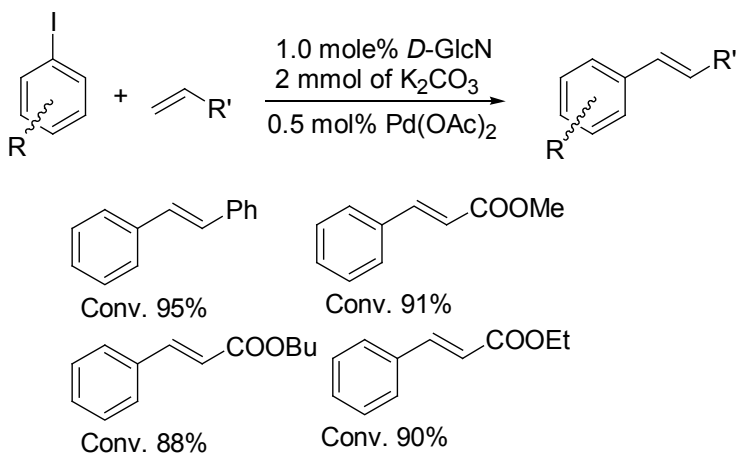

\section{1,4-共轭加成反应}

碳亲核试剂进攻共轭双键发生 1,4-加成反应，是形 成不对称碳碳键的一个重要过程. 铜催化有机锌与 $\alpha, \beta$ 不饱和酮的加成反应自被发现以来便吸引了研究者的 注意(Eq. 7). 该反应中用到的手性配体大多数是二齿配
体(如 $\mathrm{P} / \mathrm{N}, \mathrm{P} / \mathrm{O}, \mathrm{P} / \mathrm{P}$ 或 $\mathrm{N} / \mathrm{N}$ ), 在这些配体中, 磷酸吡啶配 体参与的反应具有较高的对映选择性 ${ }^{[28]}$. 目前，在 1,4共轭加成反应中应用的氨基葡萄糖衍生物配体主要有 亚磷酸酯噁唑啉类和亚磷酸酰胺类.

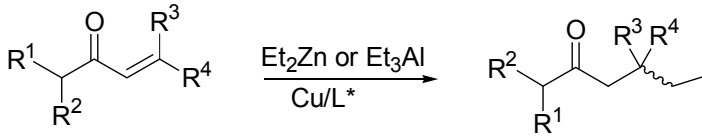

$$
\begin{aligned}
& \text { S6 } R^{1} R^{4}=C_{2} H_{4}, R^{2}=R^{3}=H \\
& \text { S7 } R^{1}=R^{2}=R^{3}=H, R^{4}=C_{5} H_{11} \\
& \text { S8 } R^{1}=R^{2}=R^{3}=H, R^{4}=i-P r
\end{aligned}
$$

Mata 等 ${ }^{[15]}$ 将配体 $\mathbf{2} \sim \mathbf{6}, \mathbf{7 a} \sim \mathbf{7 c}$ (Scheme 1) 用于铜催 化 1,4-共轭加成反应. 在底物为 S6 时, 配体 $\mathbf{2 c}$ 和 $\mathbf{2 f}$ 的 不对称诱导效果较好(64\% ee，表 3, Entries 4, 9), 其他 配体所得产物的 $e e$ 值都在 $10 \%$ 左右. 用亚磷酸酰胺部 分代替噁唑啉部分对反应有不利的影响(表 3, Entries 4, 17). 相比二乙基锌，三乙基铝为亲核试剂时，对映选择 性由 $64 \%$ 降到 5\%(表 3, Entries 4,5). 从表 3 中可以看出, 配体连有空间阻碍的联苯部分和苯基啞唑啉部分对反 应有利，啞唑啉换成亚磷酸酰胺对提高反应的收率和选 择性不利．底物 S6 的 1,4-共轭加成反应对映选择性主要 受到配体亚磷酸酯部分取代基的影响，啞唑啉部分取代 基 $\mathrm{R}$ 的影响不大. 对于底物 $\mathbf{S 7}$ 的 1,4-共轭加成反应，配 体联苯和噁唑啉部分取代基都对反应的收率和对映选 择性有影响. 配体 2c，2f 参与反应的收率及对映选择性 分别为 $85 \%$ 和 $62 \%$ ee (表 3, Entries 6,10). 噁唑啉换成亚 磷酸酰胺后，反应的收率和选择性没有提高，ee 值由

表 3 铜催化底物 $\mathbf{S 6} \sim \mathbf{S 8}$ 的不对称 1,4-共轭加成

\begin{tabular}{|c|c|c|c|c|c|c|}
\hline Entry & Ligand & Substrate & Conv. $/ \%$ & Yield/\% & $e e / \%$ & Ref \\
\hline 1 & $2 a$ & S6 & 85 & 36 & $6(S)$ & {$[15]$} \\
\hline 2 & $2 b$ & S6 & 95 & 20 & $27(S)$ & {$[15]$} \\
\hline 3 & $2 b$ & S7 & 60 & 32 & $32(R)$ & {$[15]$} \\
\hline 4 & $2 c$ & S6 & 99 & 50 & $64(S)$ & {$[15]$} \\
\hline $5^{a}$ & $2 c$ & S6 & 80 & 18 & $5(R)$ & {$[15]$} \\
\hline 6 & $2 c$ & S7 & 97 & 51 & $51(R)$ & {$[15]$} \\
\hline $7^{c}$ & $2 c$ & S7 & 94 & 48 & $78(R)$ & {$[15]$} \\
\hline 8 & $2 c$ & S8 & 94 & 94 & $68(R)$ & {$[15]$} \\
\hline 9 & $2 f$ & S6 & 88 & 61 & $64(S)$ & {$[15]$} \\
\hline 10 & $2 f$ & S7 & 92 & 85 & $62(R)$ & {$[15]$} \\
\hline 11 & $2 f$ & S8 & 96 & 90 & $80(R)$ & {$[15]$} \\
\hline 12 & $3 \mathbf{a}$ & S6 & 99 & 70 & $5(S)$ & {$[15]$} \\
\hline 13 & $4 a$ & S6 & 95 & 39 & $7(S)$ & {$[15]$} \\
\hline 14 & $5 a$ & S6 & 91 & 27 & $3(S)$ & {$[15]$} \\
\hline 15 & $6 a$ & S6 & 96 & 43 & $5(S)$ & {$[15]$} \\
\hline 16 & $7 b$ & S7 & 80 & 32 & $26(S)$ & {$[15]$} \\
\hline 17 & $7 c$ & S6 & 89 & 22 & $17(S)$ & {$[15]$} \\
\hline $18^{b}$ & $19 c$ & S7 & 100 & 49 & $90(R)$ & {$[29]$} \\
\hline $19^{a}$ & $19 c$ & S7 & 100 & 53 & $83(R)$ & {$[29]$} \\
\hline
\end{tabular}
表 3 The copper-catalyzed asymmetric conjugated 1,4-addition of $\mathbf{S 6} \sim \mathbf{S 8}$ 
32\%降到 26\%(表 3, Entries 3，16). 使用催化剂前体 $\left[\mathrm{Cu}(\mathrm{MeCN})_{4}\right] \mathrm{BF}_{4}$ 后, 对映选择性从 $51 \%$ 提高到 $78 \%$ (表 3, Entries 6 7). 配体 2c, $2 \mathbf{f}$ 同样适用于底物 $\mathbf{S 8}$ 的反应 (表 3, Entries 8, 11).

Xia等 ${ }^{[28]}$ 合成了 $D$-氨基葡萄糖衍生化的新型磷酸吡 啶配体 19a 和 19b (Scheme 6), 并首次成功应用于 $\mathrm{Cu}$ 催 化二乙基锌与查尔酮的对映选择性反应. 配体 $19 \mathrm{a} / \mathrm{Cu}(\mathrm{OAc})_{2} \cdot 2 \mathrm{H}_{2} \mathrm{O}$ 为催化剂, $\mathrm{Et}_{2} \mathrm{Zn}$ 与查尔酮反应的收 率达到 $82 \%$, 对映选择性 $70 \%$ ee, 而其他铜盐如 $\mathrm{Cu}(\mathrm{OT}$ f) $)_{2},\left[\mathrm{Cu}\left(\mathrm{CH}_{3} \mathrm{CN}\right)_{4}\right] \mathrm{BF}_{4}$ 催化反应的对映选择性大部分在 $60 \%$ ee 左右. 与配体 19a 相比, 配体 19b 参与的催化反 应的低产率和低对映选择性说明催化反应的产率和对 映选择性受联芳基的亚磷酸酯部分构型的影响. 在现有 优化的反应条件下, 4 取代查尔酮电子效应对反应没有 太大的影响, 所有的 4 取代查尔酮几乎都有对映选择性. 配体 19a $\sim 19 b$ 催化 $\mathrm{ZnEt}_{2}$ 与 2-环已烯酮类的 1,4 加成反 应的对映选择性都较差. Lega 等 ${ }^{[29}$ 将 $19 \mathrm{c}$ 用于催化底物 S7 的 1,4-共轭加成反应, 用二甲基锌、二乙基锌为亲核 试剂时对映体选择性分别为 $90 \%, 83 \%$ (表 3, Entry 18 19).

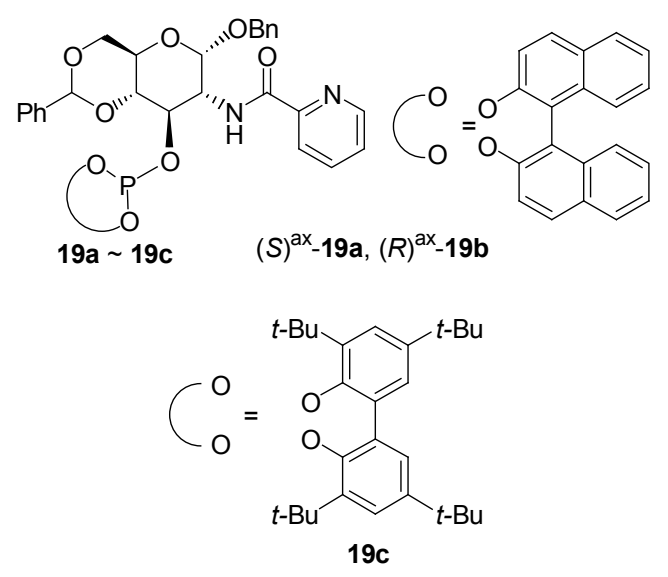

Scheme 6

\section{4 烯烃环氧化}

环氧化物是药物及精细化学品制备过程的重要中 间体. 席夫碱配体在烯烃不对称催化环氧化的反应中具 有重要的作用 ${ }^{[30]}$.

Zhao 等 ${ }^{[31]}$ 合成了化合物 20a $\sim 20 \mathrm{e}$ (Scheme 7), 用 钿一席夫碱配体催化剂 $\mathrm{MoO}_{2} \mathrm{~L}^{* 2}$ ( $\mathrm{L} *=$ chiral 2-pyridinylalcoholate)催化苯乙烯环氧化. 当催化剂: 底物 : 氧化 剂物质的量的比为 $1: 100: 150$ 时, $4 \mathrm{~h}$ 后环辛烯的环氧 化反应收率达到 60\% 70\%, $22 \mathrm{~h}$ 后反应完全(除了配体 20a). 化合物 20b 20c 表现出很高的反应活性, 在催化 剂：底物：氧化剂物质的量的比为 $1: 100000: 150000$
时催化剂的 TOFs 为 $13000 \mathrm{~h}^{-1}$. 对于没有官能团化的烯 烃而言, $\mathrm{MoO}_{2} \mathrm{~L}^{* 2} / \mathbf{2 0 a} \sim 20 \mathrm{e}$ 催化反应的对映选择性为 $25 \% e e$, 官能团化的烯烃环氧化反应的对映选择性 $53 \%$.
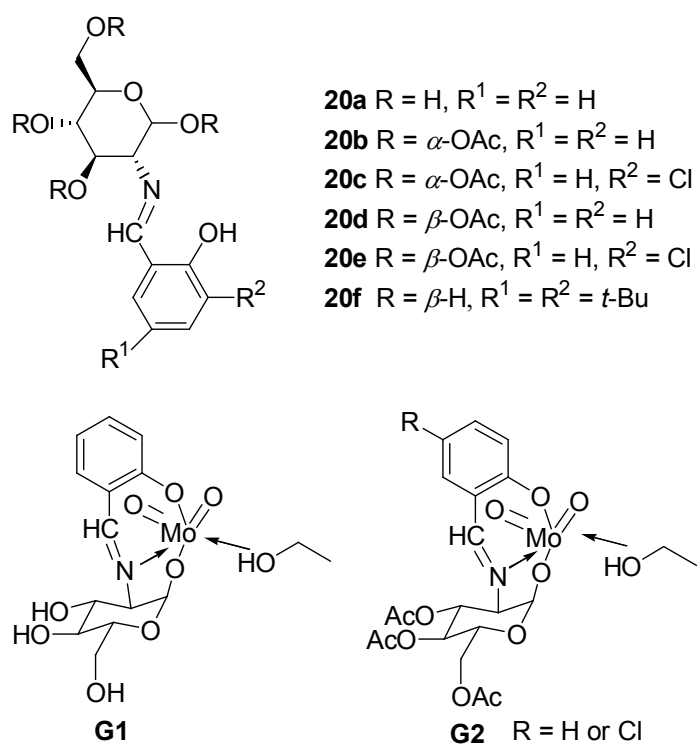

Scheme 7

Chatterjee 等 ${ }^{[2,33]}$ 合成了 $\mathrm{Ru}(\mathrm{III})$-配体络合物 $[\mathrm{Ru}(\mathrm{III})$ (TDL*)(bipy) $\left.\left(\mathrm{H}_{2} \mathrm{O}\right)\right] \mathrm{Cl} \quad\left(\mathrm{TDL}^{*}=N\right.$-3,5-di-( $t$-butyl)-salicylidine- $D$-glucosamine; bipy $=2,2$ '-bipyridine, Scheme 8 G3), 以 $t$ - $\mathrm{BuOOH}$ 为氧化剂, 催化烯烃不对称环氧化呈 现很高的催化活性. 苯乙烯、4-氯苯乙烯、4-甲基苯乙 烯、1-甲基环己烯、1,2-二氢荟都能在室温下生成相应 的环氧化物，对映选择性为 $37 \% \sim 47 \%$ ee. 4 -氯苯乙烯 反应的收率最高. $\mathrm{Ru}(\mathrm{III})$-配体络合 $\left[\mathrm{RuCl}\left(\mathrm{TDL}^{* 1}\right)\left(\mathrm{PPh}_{3}\right)_{2}\right]$ $\left[\mathrm{H}_{2} \mathrm{TDL}^{* 1}=N\right.$-(3,5-di(tertiary-butyl)salicylidine- $D$-glucosamine $)^{[34]}$ 催化苯乙烯、4-氯苯乙烯、4-甲基苯乙烯、4甲氧基苯乙烯、1-甲基环已烯、和 1,2-二氢化菜反应, 形 成的环氧化物 $e e$ 值为 $70 \% \sim 94 \%$. 由于 $t-\mathrm{BuOH}$ 与 $t$ - BuOOH 与催化剂配位的位置相同, 催化反应活性随 $t-\mathrm{BuOH}$ 的量逐渐增多而降低.与以前的钓配合物催化的 结果相比, 此催化体系获得的对映选择性较高(4-氯苯 乙烯氧化物 94\%). 该小组还用络合物 $\left[\mathrm{Mn}(\mathrm{IIII})\left(\mathrm{TDL}^{* 1}\right)(\mathrm{pic})\left(\mathrm{H}_{2} \mathrm{O}\right)\right](\mathrm{pic}=\text { picolinate })^{[35]}$ 催化苯乙 烯, 4-氯苯乙烯、4-甲基苯乙烯、4-甲氧基苯乙烯、1-甲 基环已烯和 1,2-二氢化荎的环氧化反应, $8 \mathrm{~h}$ 后转化成相 应的环氧化物，对映体过量 $50 \% \sim 62 \%$. 此配体络合物 不对称诱导的能力可能来源于糖基 $\mathrm{TDL}^{*^{1}}$ 的不对称中 心接近 $\mathrm{Mn}=\mathrm{O}$ 键, 与连接上的烯烃相互作用从而影响 对映选择性. 


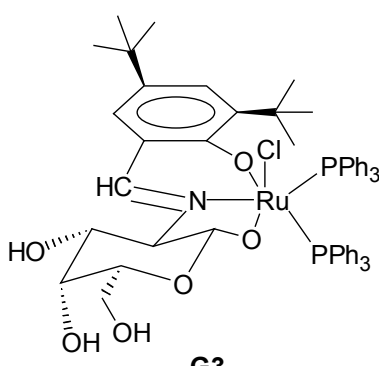

G3
$t-B u$

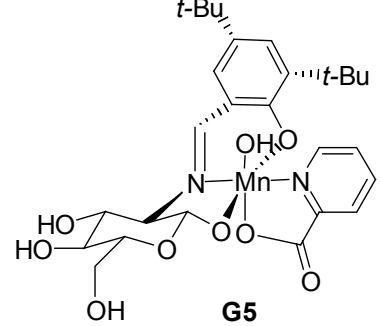

Scheme 8

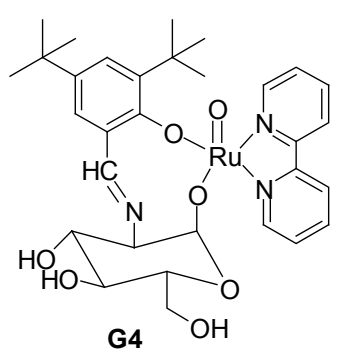

\section{5 不对称环丙化反应}

二(噁唑啉)(box)和吡啶二(噁唑啉)(pybox)是比较成 功的一类手性配体, 它们能应用在很多不对称转移反应 中. 此类配体通常都是从手性 $\beta$-氨基醇(主要从非天然 资源来)制备的. Minuth 等 $^{[36 ~ 38]}$ 由氨基葡萄糖合成了一 系列二噁唑啉配体, 并应用在不对称环丙化反应中. 此 类配体能通过对 3- $O$ 取代基的空间和电子性能进行优 化, 使其能在催化不对称环丙化反应中起到好的效果 [37].

氨基葡萄糖配体参与的不对称环丙烷化反应的结 果列于表 4 中, 从表 4 中可以看出, 3- $O$ 取代基的空间及 电子效应对不对称环丙化反应的对映选择性具有影响 (ee 值 3-O-Ac $>3-O-\mathrm{Bz}>3-O-\mathrm{Piv} ; 3-O-\mathrm{Me}>3-O-\mathrm{Bn}>$ 3-O-TES) (Eq. 8), 带有苯亚甲基椅式构象的吡喃糖环配 体 3-O acetyl 催化结果最好. 配体 Ac glucoBox (21i)催 化烯烃与乙基重氮基醋酸酯的不对称环丙化反应得到 非对映的环丙化产物, trans-和 cis-的比例为 $70: 30$, 对 映选择性 $82 \% e e$ (表 4, Entry 9). 4-甲氧基苯乙烯、1,1二苯基乙烯和 2,5-二甲基-2,4-已二烯的反应对映选择性 也很高. 配体 TMS glucoBox (21j)的催化性能优于 Ac glucoBox (21i)(表 4, Entry 10). 所有苯亚甲基保护的配 体 21a 21f 都能得到较高的收率, 但是产物的立体选 择性和对映选择性却各不相同(表 4, Entries 1 6). 配体 21a 参与反应的结果最好, trans/cis 比例为 $79: 21$, 主要 产物 trans 的对映选择性为 $93 \%$ ee, 次要产物 cis 的对映 选择性为 $82 \%$ ee (表 4, Entry 1). 配体 3-OH glucoBox (21g)参与反应的选择性中等(表 4, Entry 7). Piv glucoBox (21k)参与反应的 trans/cis 比例为 $63: 37$, trans 产物 $e e$ 值为 84\%, cis 产物 $e e$ 值为 94\%(表 4, Entry 11). 211
210 和 $\mathbf{2 1} \mathbf{h}^{[38]}$ (Scheme 9)参与的反应也能高收率获得 trans 和 cis 产物, trans/cis 比例约 $70: 30$. 苯亚甲基保护 的配体 3-O-Ac alloBox 211 和3-deoxy glucoBox 21n 只得 到外消旋的产物(表 4, Entries 12 14), 而 4,6- $O$ 环没有 保护的 Ac alloBox (21m)和 Ac 3-Deoxy glucoBox (210) 却有很好的不对称诱导性能(表 4, Entries 13，15). 苯亚 甲基保护的 3-O-AcglucoBox (21a)比没有环保护的 Ac

$$
\frac{1.1 \mathrm{~mol} \% \text { chiral ligand 21h }}{\mathrm{CH}_{2} \mathrm{Cl}_{2}, 0{ }^{\circ} \mathrm{C}, 20 \mathrm{~h}}
$$

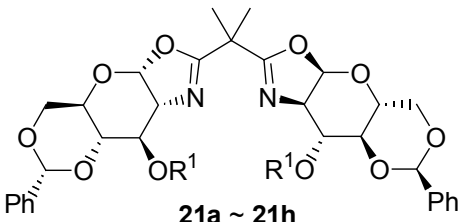

a $R^{1}=A c, b^{1}=B z, c R^{1}=$ Piv, $\mathbf{d ~ R}^{1}=M e, \mathrm{e}^{1}=B n$, $\mathbf{f} \mathrm{R}^{1}=\mathrm{TES}, \mathbf{g} \mathrm{R}^{1}=\mathrm{H}, \mathbf{h} \mathrm{R}^{1}=\mathrm{COH}$

$\mathbf{a}, \mathbf{b}, \mathbf{c}$ is ester groups; $\mathbf{d}, \mathbf{e}, \mathbf{f}$ is ether groups

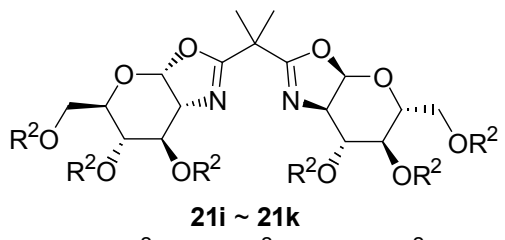

$\mathbf{i} \mathrm{R}^{2}=\mathrm{Ac}, \mathbf{j} \mathrm{R}^{2}=\mathrm{TMS}, \mathbf{k} \mathrm{R}^{2}=$ Piv
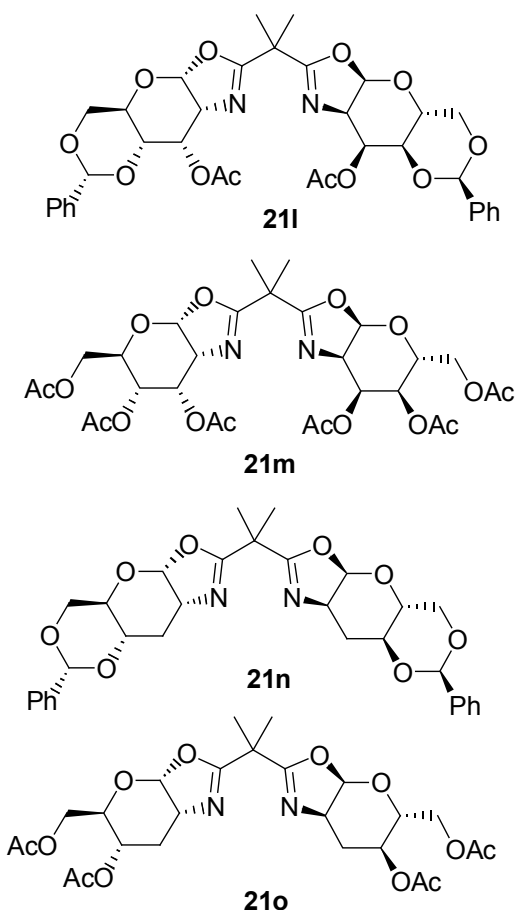

Scheme 9 
glucoBox (21i)具有更强的不对称诱导效应. 3- $O$-甲酰配 体 21h 的立体选择性比 21a 高的结果(trans $95 \%$ ee and cis 94\% ee, 表 4, Entry 8)进一步证明了 gluco-配体的规 律即 3- $O$-acyl 取代基空间体积减小配体在不对称环丙化 反应中的不对称诱导性能增加(ee 3-O-Piv 21c $<3-O-\mathrm{Bz}$ $21 \mathbf{b}<3$-O-Ac 21a $<3$ - $O$-Formyl 21h).

表 4 配体 $21 / \mathrm{Cu}$ 络合物催化不对称环丙化反应 表 4 Asymmetric cyclopropanations catalyzed by $\mathrm{Cu}$ complex of ligand $\mathbf{2 1}$

\begin{tabular}{ccccccc}
\hline Entry & Ligand & \multicolumn{7}{c}{ Yield/\% } & Trans $/$ cis $_{\text {trans }} \%$ & ee $_{\text {cis }} / \%$ & Ref. \\
\hline 1 & $\mathbf{2 1 a}$ & 90 & $79 / 21$ & 93 & 82 & {$[36]$} \\
2 & $\mathbf{2 1 b}$ & 74 & $69 / 31$ & 64 & 36 & {$[36]$} \\
3 & $\mathbf{2 1 c}$ & 90 & $64 / 36$ & 62 & 49 & {$[36]$} \\
4 & $\mathbf{2 1 d}$ & 87 & $77 / 23$ & 73 & 39 & {$[36]$} \\
5 & $\mathbf{2 1 e}$ & 95 & $62 / 38$ & 48 & 28 & {$[36]$} \\
6 & $\mathbf{2 1 f}$ & 71 & $64 / 36$ & 33 & 7 & {$[36]$} \\
7 & $\mathbf{2 1 g}$ & 87 & $68 / 32$ & 51 & 44 & {$[36]$} \\
8 & $\mathbf{2 1 h}$ & 95 & $71 / 29$ & 95 & 94 & {$[36]$} \\
9 & $\mathbf{2 1 i}$ & 60 & $70 / 30$ & 82 & 82 & {$[36]$} \\
10 & $\mathbf{2 1 j}$ & 56 & $71 / 29$ & 68 & 58 & {$[36]$} \\
11 & $\mathbf{2 1 k}$ & 86 & $63 / 37$ & 84 & 94 & {$[36]$} \\
12 & $\mathbf{2 1 1}$ & 75 & $66 / 34$ & Rac. & Rac. & {$[36]$} \\
13 & $\mathbf{2 1 m}$ & 79 & $70 / 30$ & 71 & 87 & {$[36]$} \\
14 & $\mathbf{2 1 n}$ & 86 & $69 / 31$ & Rac. & Rac. & {$[36]$} \\
15 & $\mathbf{2 1 0}$ & 75 & $74 / 26$ & 78 & 72 & {$[36]$} \\
\hline
\end{tabular}

由于二(噁唑啉)配体(glucoBox)在铜催化环丙化中 得到高的对映选择性, Irmak 等 ${ }^{[39]}$ 合成了新型二(噻唑啉) 配体 22 (Scheme 10). 配体 22 不适合 $\mathrm{Ru}$ 催化反应, 配体 22 与三氟甲烷磺酸铜 $(\mathrm{I})$ 在 $0{ }^{\circ} \mathrm{C}$ 二氯甲烷中催化烯烃的 环丙化反应, 提高了产品的收率和对映选择性, 但是对 映选择性仍然很低.

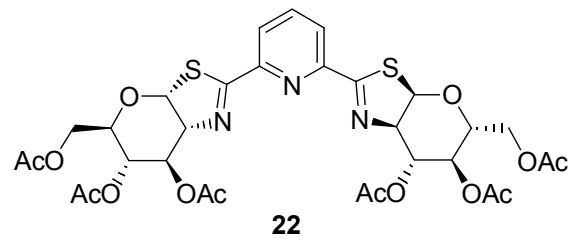

Scheme 10

\section{Henry 反应}

Subba Reddy 等 ${ }^{[40]}$ 探索了 glucoBOX (21i) 在各种醛 与硝基烷类对映选择性 Henry 反应中的应用. 以 4-溴苯甲醛和硝基甲烷的反应为模型反应, $\mathrm{Cu}(\mathrm{OAc})_{2} \cdot \mathrm{H}_{2} \mathrm{O}$ 和 glucoBOX (21i) 在乙醇中原位生成的催化剂, 反应的收 率及 $e e$ 值分别为 $83 \%, 89 \%$. GlucoBOX (21i)配体手性 $\mathrm{Cu}$ 络合物对各种芳香醛和脂肪醛的催化效果都很好.

苯甲醛在最优条件下得到相应的产物, 收率及 $e e$ 值分 别为 $85 \%, 94 \%$ (Eq. 9).

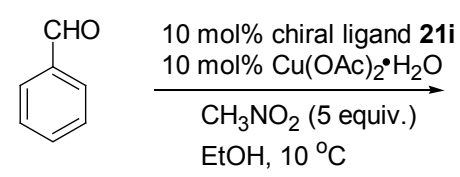

\section{7 醛类不对称加成反应}

金属有机试剂与醛的加成反应是一种有价值的合 成二级醇方法(Eq. 10). 在这反应中, 不对称反应始终是 一个挑战. 目前报道的手性配体有手性氨基醇、氨基硫 醇、二醇等. 羟基磺酰胺和二磺酰胺配体被证明是二烷 基锌加成有效的配体. 在氨基醇类配体中, $D$-氨基葡萄 糖制备的氨基醇配体有其独特的优点, 它价格低廉而且 可对立体中心进行有效修饰，从而调控配体的不对称诱 导能力.

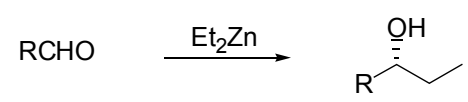

Bauer 等 ${ }^{[41]}$ 从 $D$-氨基葡萄糖衍生化合成了 $\alpha$-差基磺 酰胺配体 23a 23b (Eq. 11)，并应用于钛催化二硝基苯 甲醛、芳香族、脂肪族醛类的对映选择性加成反应. 二 乙基锌和苯甲醛在 0.1 equiv. 的配体 23a/异丙醇钛(IV)催 化下得到手性苯丙醇, 收率及 $e e$ 值分别为 $99 \%$, 97.0\%(表 5, Entry 1). 反应的收率随配体 23a 用量的减 少而急剧下降, 对映选择性变化不大. 而用 0.1 equiv. 23b 为配体时, 反应的收率最高 $98 \%$, 对映选择性却很

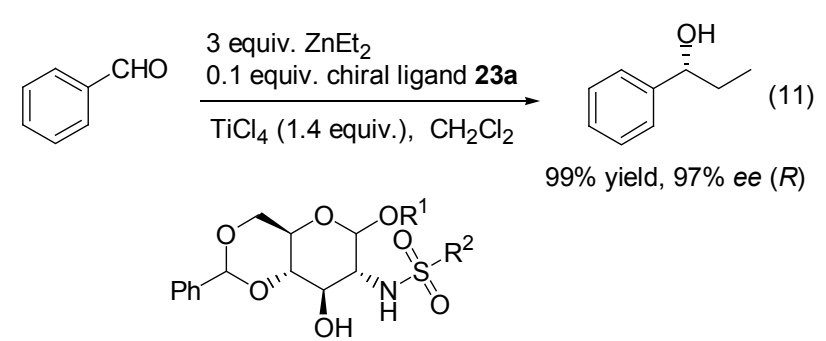

$$
\begin{aligned}
& \text { 23a } \alpha-\mathrm{R}^{1}=\mathrm{Me}, \mathrm{R}^{2}=4-\mathrm{Me}-\mathrm{C}_{6} \mathrm{H}_{4} \\
& \text { 23b } \beta-\mathrm{R}^{1}=\mathrm{Bn}, \mathrm{R}^{2}=4-\mathrm{Me}-\mathrm{C}_{6} \mathrm{H}_{4} \\
& \text { 23c } \alpha-\mathrm{R}^{1}=\mathrm{Me}, \mathrm{R}^{2}=\mathrm{Me} \\
& \text { 23d } \alpha-\mathrm{R}^{1}=\mathrm{Me}, \mathrm{R}^{2}=\mathrm{CF}_{3} \\
& \text { 23e } \beta-\mathrm{R}^{1}=\mathrm{Me}, \mathrm{R}^{2}=4-\mathrm{Me}-\mathrm{C}_{6} \mathrm{H}_{4} \\
& \text { 23f } \beta-\mathrm{R}^{1}=\mathrm{Me}, \mathrm{R}^{2}=3,5-\mathrm{CF}_{3}-\mathrm{C}_{6} \mathrm{H}_{3}
\end{aligned}
$$

23g $\alpha-\mathrm{R}^{1}=\mathrm{Me}, \mathrm{R}^{2}=$

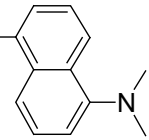

23h $\alpha-\mathrm{R}^{1}=\mathrm{Me}, \mathrm{R}^{2}=$ 
低(10\%ee，表 5, Entry 2). 配体 23a 对其他芳基醛类的 加成反应具有很好的适用性，对映选择性在 $86 \% \sim 90 \%$. 此外, 该小组还考察了磺酰基部分的结构及糖环 1 位取 代基构型对不对称诱导的影响 ${ }^{[42]}$. 立体位阻小的甲砜 胺配体 23c 的选择性只有 30\% ee(表 5, Entry 3). 在 0.1 equiv.配体 23d 的存在下, 苯甲醛在 $1.5 \mathrm{~h}$ 内反应完全, 产物的 $e e$ 值达 94\%(表 5, Entry 4). 由于三氟甲基有很强 的吸电子能力, 同时它相对于异丙基来说是体积比较大 的取代基, 当用 0.01 equiv. 23d 时, 反应的对映选择性 也保持在同等水平, 但反应的收率有所降低. 1 位羟基 变为 $\beta$-甲氧基后的 $23 \mathrm{e}$ 不对称诱导效应较低 $39 \% e e$, 表 5, Entry 5). 配体 23g 的催化性能与配体 23a 类似 (94\% $e e$, 表 5, Entry 6).

表 5 钛络合物催化二乙基锌与苯甲醛的不对称加成反应 表 5 Enantioselective addition of diethylzinc to benzaldehyde catalyzed by Ti complex

\begin{tabular}{cccccc}
\hline Entry & Ligand & Time $/ \mathrm{h}$ & Yield $/ \%$ & $e e / \%$ & Ref. \\
\hline 1 & 23a & 3 & 99 & $97(R)$ & {$[40]$} \\
2 & 23b & 5 & 98 & $10(R)$ & {$[40]$} \\
3 & 23c & 20 & 96 & $30(R)$ & {$[41]$} \\
4 & 23d & 1.5 & 92 & $94(R)$ & {$[41]$} \\
5 & 23e & 2 & 88 & $39(R)$ & {$[41]$} \\
6 & 23g & 12 & 98 & $94(R)$ & {$[41]$} \\
\hline
\end{tabular}

\section{8 末端炔烃与羰基的加成反应}

末端炔烃与羰基化合物的对映选择性加成反应是 制备手性炔丙醇的有效方法. Bauer 等 ${ }^{[43]}$ 第一次将 $D$-氨 基葡萄糖衍生物应用于钛催化苯乙炔与苯甲醛等醛的 加成反应. 当配体 23a : $\mathrm{Et}_{2} \mathrm{Zn}: \mathrm{Ti}(\mathrm{O} i-\mathrm{Pr})_{4}$ 物质的量的 比为 $1: 2: 7$ 时, 反应的化学选择性高, 但对映选择性 很低. 经反应条件优化后发现, 以二氯甲烷为溶剂, 配体 23f : $\mathrm{Ti}(\mathrm{O} i-\mathrm{Pr})_{4}$ 物质的量的比为 $1: 6$ 时为最佳. 以 $23 f$ 为配体, 二甲基锌的反应具有较高的化学选择性和对映 选择性(Eq. 12). 以 $23 \mathbf{f}$ 为配体时, 苯乙炔与芳基醛、脂 环族醛类的反应，对映体选择性较高，而与线性的脂肪 醛反应时产物的 $e e$ 值较低.

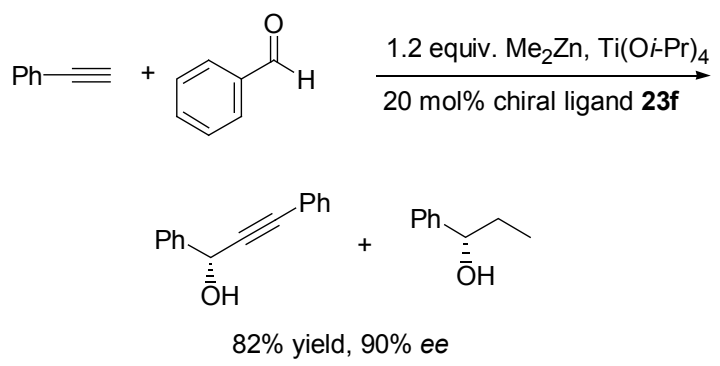

Emmerson 等 ${ }^{[44]}$ 合成了糖基骨架上构象受限的氨基 醇配体, 考察了氨基醇配体 $\mathbf{2 4 a} \sim 24 \mathrm{~g}$ 催化炔类与醛的
不对称加成反应. 配体 24a 参与的苯乙炔和环已基甲醛 在室温下反应只得到了仲醇. $40{ }^{\circ} \mathrm{C}$ 下反应得到收率 95\%, ee 值 $97 \%$ 的炔加成产物. 而配体 $\mathbf{2 4 b}$ 参与反应的 收率为 $58 \%, e e$ 值 $99 \%$. 配体 $\mathbf{2 4 c} \sim \mathbf{2 4 f}$ 的不对称诱导效 应低于 24b, 配体 $24 \mathbf{f}$ 的催化活性高, 收率可达 $96 \%$. 配 体 24g 的催化性能最佳, 收率及对映选择性分别为 $94 \%$, 99\% (Eq. 13).
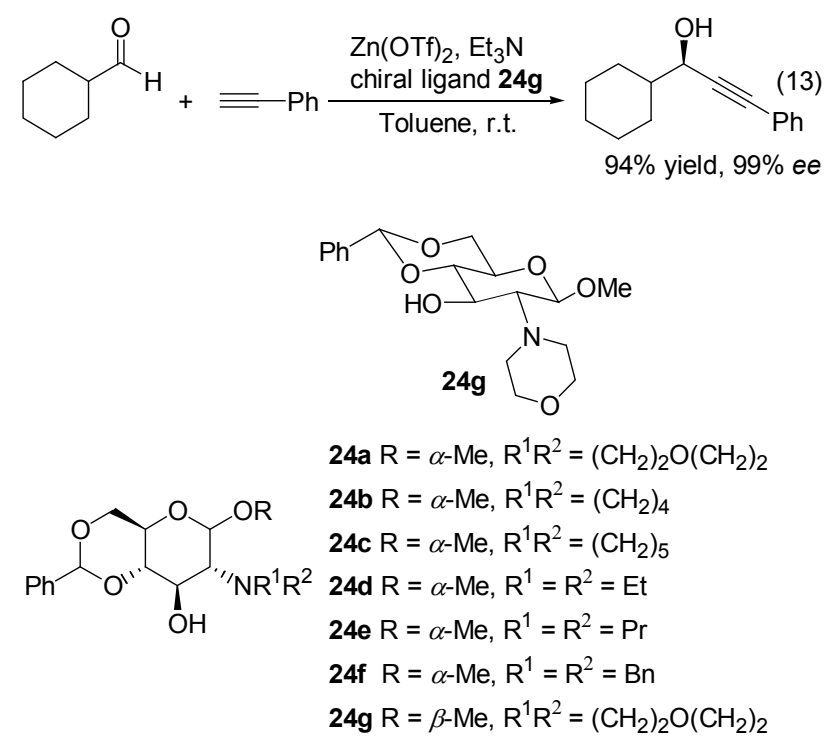

\section{9 羟醛反应}

Shen 等 ${ }^{[45}$ 考察了氨基葡萄糖基氨基醇类配体对羟 醛反应的催化性能, 在 $D$-氨基葡萄糖盐酸盐(10 $\mathrm{mol} \%$ ) 和催化量的 $\mathrm{Et}_{3} \mathrm{~N}$ 的催化下, 室温反应得到高收率的目 标产物, 但是 $e e$ 值却很低. $24 \mathrm{~h}$ 和 $24 \mathbf{i}$ 不能催化此反应, 氨基醇 $24 \mathbf{j}$ 参与反应的 $(S)$-构型产物收率(95\%)和 $e e$ 值 (15\%)都有所升高. 配体 24k 参与反应的产物对映选择 性提高到 $41 \%$ ee (Entry 4), 优化反应条件后发现, 在水 中于 $0{ }^{\circ} \mathrm{C}$ 及 $10 \mathrm{~mol} \%$ 配体的条件下, 反应 $4 \mathrm{~d}$ 后收率为 $99 \%$, 对映选择性为 $55 \%$ (Eq. 14), 而在 $\mathrm{CH}_{2} \mathrm{Cl}_{2}$ 中反应 $e e$ 值升到 $67 \%$, 但是收率降到 $91 \%$. 而用配体 241 时, 只 得到外消旋的产物, 说明伯胺基团的重要性. 研究发现 丙酮与各种静红底物在上述催化条件下皆能反应，溴取 代的静红底物获得最高的对映选择性 75\%, 其他大部分 在 $60 \% \sim 70 \%$.

\section{0 不对称氢化反应}

Mazuela 等 ${ }^{[46]}$ 用配体 1a, 1d 1f (Eq. 15) 催化 $(E)$-和 (Z)-三取代和 1,1-二取代烯烃不对称加氢反应, 对映选 择性达 99\%, 且铱催化剂能回收利用. 催化三取代的底 物 S9 和 S10 的不对称氢化反应, Ir/1e 催化效果最好(表 6, Entries 5 6). 用配体 $\mathbf{1 d} \sim 1 \mathbf{e}$ 得到的对映选择性高, 


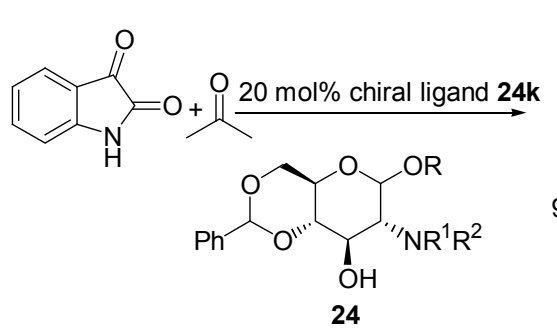<smiles>CC(=O)CC1(O)C(=O)Nc2ccccc21</smiles>

$99 \%$ yield, $55 \%$ ee $(S)$

h $\mathrm{R}=\beta-\mathrm{Me}, \mathrm{R}^{1}=\mathrm{H}, \mathrm{R}^{2}=\mathrm{COCH}_{3}$

$\mathrm{i} \mathrm{R}=\beta-\mathrm{Bn}, \mathrm{R}^{1}=\mathrm{H}, \mathrm{R}^{2}=\mathrm{COCH}_{3}$

$\mathrm{j} \mathrm{R}=\beta$-Me, $\mathrm{R}^{1}=\mathrm{H}, \mathrm{R}^{2}=\mathrm{H}$

$\mathbf{k}=\beta-\mathrm{Bn}, \mathrm{R}^{1}=\mathrm{H}, \mathrm{R}^{2}=\mathrm{H}$

$\mathrm{I} \mathrm{R}=\beta-\mathrm{Bn}, \mathrm{R}^{1}=\mathrm{H}, \mathrm{NH} ; \mathrm{R}^{2}=\mathrm{HN}_{\mathrm{NH}}$

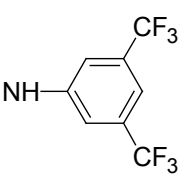

但是 1d 的反应活性低(表 6 , Entries 3 6). 1a 的催化活性 高但对映选择性低(表 6, Entries 1～2). 带有庞大的芳基 膦配体 $1 \mathrm{~h}$ 催化性能与配体 1e 类似(表 6, Entries 5 8). $(Z)-\mathbf{S} 11, \mathbf{S} 12$ 的氢化反应通常比 $(E)-\mathbf{S} 11, \mathbf{S} 12$ 的获得的对 映选择性低, 催化反应的立体选择性受配体的影响大, $1 \mathrm{~h}$ 参与反应的催化效果好说明膦配体的空间位阻大对 反应有利(表 6, Entries 9 10). S13 不对称氢化得到对映 选择性 $99 \%$, 该催化体系具有较好的底物适用性, 不对 称加氢反应 $e e$ 值也都比较高.

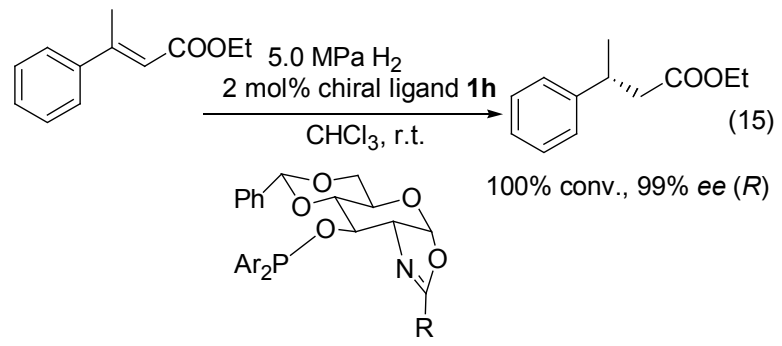

1h $\mathrm{R}=\mathrm{Ph}, \mathrm{Ar}=\mathrm{Tol}$

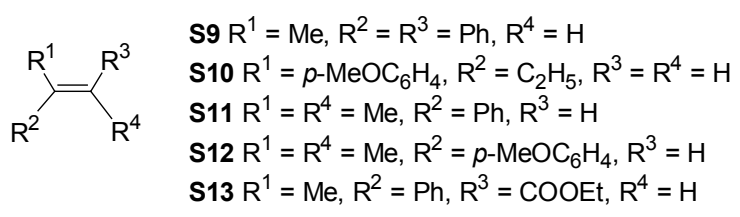

表 6 铱络合物催化 $S 9 \sim S 13$ 不对称氢化反应

表 6 Ir-catalyzed asymmetric hydrogenation of $\mathbf{S 9} \sim \mathbf{S 1 3}$

\begin{tabular}{cccccc}
\hline Entry & Substrate & Ligand & Conv./\% & $e e / \%$ & Ref. \\
\hline 1 & S9 & 1a & 100 & $91(R)$ & {$[45]$} \\
2 & S10 & $\mathbf{1 a}$ & 100 & $87(S)$ & {$[45]$} \\
3 & S9 & $\mathbf{1 d}$ & 64 & $95(R)$ & {$[45]$} \\
4 & S10 & $\mathbf{1 d}$ & 97 & $93(S)$ & {$[45]$} \\
5 & S9 & $\mathbf{1 e}$ & 100 & $95(R)$ & {$[45]$} \\
6 & S10 & $\mathbf{1 e}$ & 100 & $94(S)$ & {$[45]$} \\
7 & S9 & $\mathbf{1 h}$ & 100 & $96(R)$ & {$[45]$} \\
8 & S10 & $\mathbf{1 h}$ & 100 & $94(S)$ & {$[45]$} \\
9 & S11 & $\mathbf{1 h}$ & 100 & $87(S)$ & {$[45]$} \\
10 & S12 & $\mathbf{1 h}$ & 100 & $89(S)$ & {$[45]$} \\
11 & $\mathbf{S 1 3}$ & $\mathbf{1 h}$ & 100 & $99(R)$ & {$[45]$} \\
\hline
\end{tabular}

\section{1 结论与展望}

不对称反应是有机化学研究的一个热点课题, 手性 配体及手性催化剂构效关系的研究一直是不对称催化 研究的重点. 氨基葡萄糖是一类富手性中心的天然手性 源，易于修饰改性，以氨基葡萄糖衍生物为手性配体在 结构设计上具有很大的调整空间, 有望发现高活性、高 选择性、底物适用范围广的催化体系. 氨基葡萄糖基二 芳基膦类配体和亚磷酸酯类配体在烯丙基烷基化反应、 Heck 反应、1,4-共轭加成反应中都有很好的不对称诱导 性能, 有的能达到 $99 \%$ ee 以上. 从催化反应的结果看, 要提高立体选择性, 改性的配体配体原子要尽可能靠近 氨基葡萄糖环，只有这样氨基葡萄糖环上的手性中心对 催化反应的诱导效应才高. 随着研究的深入，氨基葡萄 糖基配体能够催化的不对称反应类型也在日益增多. 作 为天然手性配体的改性及其在不对称催化反应中的应 用研究的广泛开展, 有望对自然界酶催化的不对称反应 有进一步的认识, 对开发新型手性催化剂具有重要的意 义.

\section{References}

[1] Fu, B.; Xiao, Y.-M.; Tan, Z.-H.; Dong, Y.-H.; Li, N. Chin. J. Org. Chem. 2006, 26, 899 (in Chinese).

(傅滨, 肖玉梅, 覃兆海, 董燕红, 李楠, 有机化学, 2006, 26, 899.)

[2] Cui, P.-L.; Liu, H.-Y.; Zhang, D.-N.; Wang, C. Chin. J. Org. Chem. 2012, 32, 1401 (in Chinese).

(崔朋雷, 刘海燕, 张冬暖, 王春, 有机化学, 2012, 32, 1401.)

[3] Wang, Z.-T.; Zhang, Y.-S.; Wang, S.-C.; Xia, D.-H. Chin. J. Org. Chem. 2007, 27, 143 (in Chinese).

(王宗廷, 张云山, 王书超, 夏道宏, 有机化学, 2007, 27, 143.)

[4] Wang, S.-Y.; Ji, S.-J. Chin. J. Org. Chem. 2008, 28, 181 (in Chinese).

(汪顺义, 纪顺俊, 有机化学, 2008, 28, 181.)

[5] Sun, W.; Xia, C.-G.; Wang, A.-Q. Acta Chim. Sinica 2002, 60, 162 (in Chinese).

(孙伟, 夏春谷, 王爱勤, 化学学报, 2002, 60, 162.)

[6] Gou, S.-H.; Ye, Z.-B.; Cai, X.-X.; Liu, M.; Jiang, W.-C. Chin. J. Org. Chem. 2012, 32, 1136 (in Chinese).

(苟绍华, 叶仲斌, 蔡潇潇, 刘曼, 蒋文超, 有机化学, 2012, 32, 1136.)

[7] Cui, P.-L.; Liu, H.-M.; Guo, X.-M.; Zhang, D.-N.; Wang, Y.-N.; Wang, C. Chin. J. Org. Chem. 2012, 32, 1 (in Chinese). (崔朋雷, 刘卉敏, 果秀敏, 张冬暖, 王彦恩, 王春, 有机化学, 2012, 32, 1.)

[8] Xing, A.-P.; Wang, L.-L. J. Mol. Catal. 2011, 25, 180 (in Chinese). (邢爱萍，王来来，分子催化, 2011, 25, 180.)

[9] Fu, Y.-Q.; Tao, J.-Z. Chin. J. Org. Chem. 2008, 28, 44 (in Chinese). (傅玉琴, 陶京朝, 有机化学, 2008, 28, 44.)

[10] Yonehara, K.; Hashizume, T.; Mori, K.; Ohe, K.; Uemura, S. J. Org. Chem. 1999, 64, 9374.

[11] Yonehara, K.; Hashizume, T.; Mori, K.; Ohe, K.; Uemura, S. Chem. Commun. 1999, 415.

[12] Hashizume, T.; Yonehara, K.; Ohe, K.; Uemura, S. J. Org. Chem. 2000, 65, 5197. 
[13] Mata, Y.; Diéguez, M.; Pàmies, O.; Claver, C. Org. Lett. 2005, 7, 5597.

[14] Mata, Y.; Pàmies, O.; Diéguez, M. Chem. Eur. J. 2007, 13, 3296.

[15] Mata, Y.; Diéguez, M.; Pàmies, O.; Biswas, K.; Woodward, S. Tetrahedron: Asymmetry 2007, 18(13), 1613.

[16] Mata, Y.; Pàmies, O.; Diéguez, M. Adv. Synth. Catal. 2009, 351(18), 3217.

[17] Mata, Y.; Carmen C.; Diéguez, M.; Pàmies, O. Tetrahedron: Asymmetry 2007, 17(23), 3282.

[18] Tollabi, M.; Framery, E.; Henry, C.-G.; Sinou, D. Tetrahedron: Asymmetry 2003, 14(21), 3329.

[19] Johannesen, S. A.; Glegoła, K.; Sinou, D.; Framery, E.; Troels, S. Tetrahedron Lett. 2007, 8(20), 3569.

[20] Glegoła, K.; Framery, E.; Henry, C. G.; Pietrusiewicz, M. P.; Denis, S. Tetrahedron 2007, 63(30), 7133.

[21] Konovets, A.; Glegoła, K.; Penciu, A.; Framery, E.; Jubault, P.; Henry, C. G.; Pietrusiewicz, M. P.; Quirion, J. C.; Sinou, D. Tetrahedron: Asymmetry 2005, 16(19), 3183.

[22] Glegoła, K.; Johannesen, Sine. A.; Thim, L.; Henry, C. G.; Skrydstrup, T.; Framery, E. Tetrahedron Lett. 2008, 49, 6635.

[23] Shen, C.; Xia, H. J.; Zheng, H.; Zhang, P. F.; Chen, X. Z. Tetrahedron: Asymmetry 2010, 21, 1936.

[24] Khiar, N.; Suarez, B.; Fernández, I. Inorg. Chim. Acta 2006, 359, 3048.

[25] Khiar, N.; Navas, R.; Fernández, I. Tetrahedron Lett. 2012, 53, 395.

[26] Yonehara, K.; Mori, K.; Hashizume, T.; Chung, K., G.; Ohe, K.; Uemura, S. J. Organomet. Chem. 2000, 603, 40.

[27] Amini, M.; Etemadi, H. Chem. Papers 2013, 67(7), 759.

[28] Xia, H.-J.; Yan, H.; Shen, C.; Shen, F.-Y.; Zhang, P. F. Catal. Commun. 2011, 16(1), 155.

[29] Lega, M.; Margalef, J.; Ruffo, F.; Pàmies, O.; Diéguez, M. Tetrahedron: Asymmetry 2013, 24, 995.
[30] Costamagna, J.; Lillo, L. E.; Matsuhiro, B.; Noseda, M. D.; Villagran, M. Carbohydr. Res. 2003, 338, 1535.

[31] Zhao, J.; Zhou, X. G.; Santos, A. M.; Herdtweck, E.; Romão, C. C.; Kühn, F. Dalton. Trans. 2003, 19, 3736.

[32] Chatterjee, D.; Basak, S.; Mitra, A.; Sengupta, A.; Bras, J. L.; Muzart, J. Inorg. Chim. Acta 2006, 359, 1325.

[33] Chatterjee, D.; Basak, S.; Mitra, A.; Sengupta, A.; Bras, J. L.; Muzart, J. Catal. Commun. 2005, 6, 459.

[34] Chatterjee, D.; Basak, S.; Riahi, A.; Muzart, J. J. Mol. Catal. 2006, $255(1 \sim 2), 283$.

[35] Chatterjee, D.; Basak, S.; Riahi, A.; Muzart, J. Catal. Commun. 2007, 8(9), 1345

[36] Minuth, T.; Irmak, M.; Groschner, A.; Lehnert, T.; Boysen, M. M. K. Eur. J. Org. Chem. 2009, 997.

[37] Minuth, T.; Boysen, M. M. K. Synlett 2008, 1483.

[38] Minuth, T.; Boysen, M. M. K. Beilstein J. Org. Chem. 2010, 6, 1.

[39] Irmak, M.; Lehnert, T.; Boysen, M. M. K. Tetrahedron Lett. 2007, 48,7890 .

[40] Subba Reddy, B. V.; George, J. Tetrahedron: Asymmetry 2011, 22, 1169.

[41] Bauer, T.; Tarasiuk, J.; Pasniczek, K. Tetrahedron: Asymmetry 2002, 13(1), 77.

[42] Bauer, T.; Smolinski, S. Appl. Catal. A 2010, 375, 247.

[43] Bauer, T.; Smolinski, S.; Gawel, P.; Jurczak, J. Tetrahedron Lett. 2011, 52, 4882.

[44] Emmerson, D. P. G.; Hems, W. P.; Davis, B. G. Org. Lett. 2006, 8, 207.

[45] Shen, C.; Shen, F.; Xia, H. J.; Zhang, P. F.; Chen, X. Z. Tetrahedron: Asymmetry 2011, 22, 708.

[46] Mazuela, J.; Pàmies, O.; Diéguez, M. Eur. J. Inorg. Chem. 2013, 2139.

(Qin, X.) 